\title{
Possible role of pre-monsoon sea surface warming in driving the summer monsoon onset over the Bay of Bengal
}

\author{
Kuiping $\mathrm{Li}^{1,2,3} \cdot$ Yanliang Liu ${ }^{1} \cdot$ Yang Yang $^{1} \cdot \mathrm{Zhi} \mathrm{Li}^{1} \cdot$ Baochao Liu $^{1} \cdot \mathrm{Liang} \mathrm{Xue}^{1} \cdot$ \\ Weidong Yu ${ }^{1,4}$
}

Received: 29 December 2014 / Accepted: 4 October 2015 / Published online: 13 October 2015

(c) The Author(s) 2015. This article is published with open access at Springerlink.com

\begin{abstract}
Sea surface temperature (SST) reaches its annual maximum just before the summer monsoon onset and collapses soon after in the central areas of the Bay of Bengal (BoB). Here, the impact of the peak in the pre-monsoon SST on triggering the earliest monsoon onset in the $\mathrm{BoB}$ is investigated, with a focus on the role they play in driving the firstbranch northward-propagating intra-seasonal oscillations (FNISOs) over the equatorial Eastern Indian Ocean (EIO). During the calm pre-monsoon period, sea surface warming in the BoB could increase the surface equivalent potential temperature $\left(\theta_{\mathrm{e}}\right)$ in several ways. Firstly, warming of the sea surface heats the surface air through sensible heating, which forces the air temperature to follow the SST. The elevated air surface temperature accounts for $30 \%$ of the surface $\theta_{\mathrm{e}}$ growth. Furthermore, the elevated air temperature raises the water vapor capacity of the surface air to accommodate more water vapor. Constrained by the observation that the surface relative humidity is maintained nearly constant during the monsoon transition period, the surface specific humidity exhibits a significant increase, according to the ClausiusClapeyron relationship. Budget analysis indicates that the additional moisture is primarily obtained from sea surface
\end{abstract}

Weidong Yu

wdyu@ fio.org.cn

1 Center for Ocean and Climate Research, First Institute of Oceanography, SOA, Qingdao 266061, China

2 Institute of Oceanology, Chinese Academy of Sciences, Qingdao 266071, China

3 University of the Chinese Academy of Sciences, Beijing 10049, China

4 Laboratory for Regional Oceanography and Numerical Modeling, Qingdao National Laboratory for Marine Science and Technology, Qingdao 266071, China evaporation, which also exhibits a weak increasing trend due to the sea surface warming. In this way, it contributes about $70 \%$ to the surface $\theta_{\mathrm{e}}$ growth. The rapid SST increase during the pre-monsoon period preconditions the summer monsoon onset over the BoB through its contributions to significantly increase the surface $\theta_{\mathrm{e}}$, which eventually establishes the meridional asymmetry of the atmospheric convective instability in the EIO. The pre-established greater convective instability leads to the FNISO convections, and the summer monsoon is triggered in the BoB region.

Keywords SST $\cdot$ Monsoon onset $\cdot$ Intra-seasonal oscillation · Bay of Bengal

\section{Introduction}

The Asian monsoon is one of the most significant climate systems worldwide. A distinct seasonal contrast occurs, resulting from complex ocean-atmosphere-land interactions that respond to the seasonal variations of solar radiation (Webster 2006). The transition of the Asian monsoon from winter to summer is characterized by an abrupt change in the general circulation patterns, which initially occurs in the southern part of the Bay of Bengal (BoB) (Lau and Yang 1997; Wu and Zhang 1998; Wang and LinHo 2002; Li and Zhang 2009; Li et al. 2011).

The onset of the Asian summer monsoon is crucial for society, as it stops the heat wave and starts the rainy season, allowing the growth season for agriculture around South Asia to begin. Previous studies have proposed many factors that are related to the onset of the monsoon (Krishnamurti et al. 1981; Wu and Zhang 1998; Flatau et al. 2001; Annamalai et al. 2005; Ding and He 2006; Tong et al. 2009). Nevertheless, recently coupled models remain unsuccessful 
in capturing this pronounced feature (Sperber et al. 2013). In fact, the summer monsoon starts off explosively in the $\mathrm{BoB}$ and is always accompanied with the development of strong convective systems (Hsu et al. 1999). Understanding the possible role of the ocean in driving the strong convective systems is the major motivation of the present study.

Before the summer monsoon onset, strong sea surface heating makes the central region of the BoB the warmest in the tropical Indian Ocean. This high sea surface temperature (SST) is considered to be responsible for the development of convective systems, which then trigger the summer monsoon. Jiang and $\mathrm{Li}$ (2011) reported that rapid sea surface warming in the central BoB region leads to a northward jump of the axis of warmest SST from the equatorial Eastern Indian Ocean (EIO). The warmest SST in the central BoB may precondition the convective systems through destabilizing the local atmosphere. Wu et al. (2012) attributed the critical convective systems to strong onset vortices that could be identified in about half of the years between 1979 and 2009. They argued that the surface sensible heating induced by the high SST over the warm southeastern $\mathrm{BoB}$ is of vital importance for the genesis of the vortices.

Through climatological studies, it was found that the monsoon onset is phase-locked to the wet episode of climatological intra-seasonal oscillations (ISOs) (Wang and $\mathrm{Xu}$ 1997; LinHo and Wang 2002). The northward-propagating ISOs may initiate the onset by transferring moisture and momentum from the deep tropics (Zhou and Murtugudde 2014). In the BoB region, Li et al. (2013) identified these events as the first-branch northward-propagating ISOs (FNISOs) for each year, by taking seasonality into consideration. FNISOs are a unique type of ISO events that mark the transition between the eastward-propagating Madden-Julian Oscillations (MJOs) in winter (Madden and Julian 1971, 1972) and the northward-propagating monsoon ISOs in summer (Yasunari 1979). Meanwhile, FNISOs exert strong environmental modulations on the monsoon onset vortices during their northward movement in the BoB ( $\mathrm{Li}$ et al. 2015).

In the composite map of the summer monsoon onset (Fig. 1), it is obvious that the sustained southwesterlies are established just after the first northward movement of the convection entering into the $\mathrm{BoB}$. Also, there is a striking sea surface warming in the central $\mathrm{BoB}$ region during the monsoon transitional period. SST maximizes two pentads before the FNISOs, with a value of $>30^{\circ} \mathrm{C}$ around $10^{\circ} \mathrm{N}$. During other periods, the SST is generally maximum at the equator within the EIO. The phase-locked relationships among the sea surface warming in the central BoB region, the FNISOs and the established southwesterlies have been verified with buoy-based in situ observations (Yu et al. 2012). Nevertheless, the role of the pre-monsoon sea surface warming in inducing the FNISOs has not been clearly addressed yet.

The present study was conducted to explore the potential impacts of oceanic processes on the summer monsoon onset in the BoB region. Specifically, the aim was to identify the role of the pre-monsoon SST in driving the FNISOs and hence initiating the summer monsoon over the BoB. The data and methods for this study are described in Sect. 2. In Sect. 3, we propose the FNISOs as an appropriate index to predict the summer monsoon, through comparison with the efficiency of other indices at determining the monsoon onset. The processes by which the pre-monsoon sea surface warming impacts on the FNISOs are presented in Sect. 4. Finally, conclusions and a discussion of the results are given.

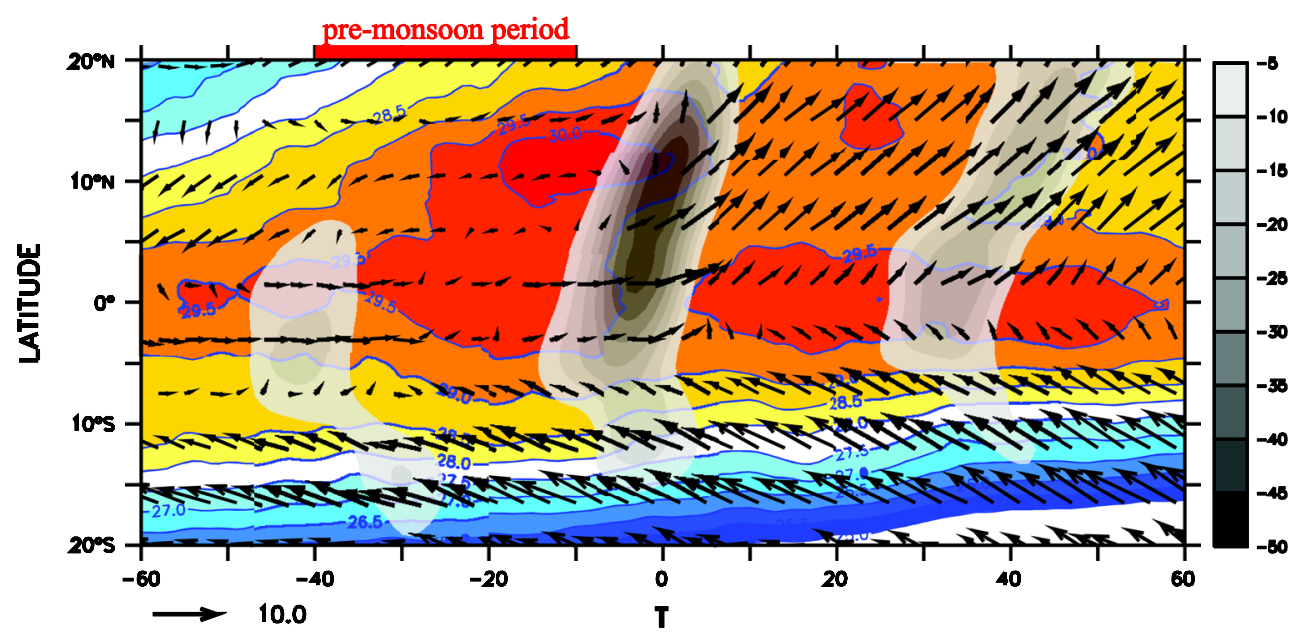

Fig. 1 Composite time-latitude sections of surface winds (vectors, $\mathrm{m} \mathrm{s}^{-1}$ ), SST (color shading, ${ }^{\circ} \mathrm{C}$ ) and 20-70-day outgoing longwave radiation anomalies (grey shading, $\mathrm{W} \mathrm{m}^{-2}$ ) along $85^{\circ}-95^{\circ} \mathrm{E}$ during 1990-2009. The vertical axis denotes the latitude and the horizontal axis is the relative time, with day 0 representing the date when the maximum FNISO convection arrives at $10^{\circ} \mathrm{N}$ along $85^{\circ}-95^{\circ} \mathrm{E}$. The FNISO event is selected in accordance with Li et al. (2013). The premonsoon period is defined as day -40 to day -10 


\section{Data and methods}

Three-dimensional daily atmospheric fields including horizontal winds, p-vertical velocity, specific humidity, relative humidity and air temperature are derived from the ERAInterim reanalysis (Dee et al. 2011). The analyzed daily SST data are from National Oceanic and Atmospheric Administration (NOAA) Optimum Interpolation (OI) analysis (Reynolds et al. 2007). Observed daily outgoing longwave radiation (OLR) (Liebmann and Smith 1996) from NOAA is employed as the proxy for convection. The daily precipitation and evaporation data from the ERA-Interim reanalysis are also used here. All the above data sets are selected from 1990 to 2009.

To compensate the results derived from the reanalysis data, the in situ buoy-based data, supported by the Research Moored Array for African-Asian-Australian Monsoon Analysis and Prediction (RAMA) (McPhaden et al. 2009) is also analyzed in this study. The parameters include air surface temperature, surface humidity and SST derived from three buoys located at $8^{\circ} \mathrm{N}, 12^{\circ} \mathrm{N}$, and $15^{\circ} \mathrm{N}$, and $90^{\circ} \mathrm{E}$. The above data are adopted from the period 2008-2012.

OLR is applied with a 20-70-day band-passed filter to isolate the intra-seasonal anomalies, and other analyzed dynamic and thermodynamic variables are preprocessed using a 5-day running mean. For the atmospheric variables in the ERA-Interim data, values at $1000 \mathrm{hPa}$ are simply considered as the sea surface values for the present study.

\section{FNISOs and the BoB summer monsoon onset}

Along with the summer monsoon onset, some dramatic changes occur in the general circulations over the monsoon regions. For example, there is a burst of surface westerlies, a sudden increase in convective rainfall, and a switch of the meridional temperature gradient (MTG), among other changes (e.g., Wang et al. 2004; Wang and LinHo 2002; Mao and Wu 2007). These abrupt changes are usually associated with the development of local convective events, thus it is reasonable to define the summer monsoon onset based on the occurrence of the above events in the BoB. After this, the feasibility of the FNISOs in defining the $\mathrm{BoB}$ monsoon onset is confirmed by comparing the index with some other indices derived from certain circulation features. A composite is taken based on a reference date of when the FNISOs arrive at $7.5^{\circ}-12.5^{\circ} \mathrm{N}$ and $85^{\circ}-95^{\circ} \mathrm{E}$, that is, the OLR anomalies reach their minimum values over the above region; this method is performed in accordance with $\mathrm{Li}$ et al. (2013). Then the onset pentad is defined as the 5 -day period around the reference date (day -2 to day +2 ).

A burst of sustained surface westerlies is often used to detect the summer monsoon onset date (e.g., Wang et al. 2004). During the monsoon transitional period, the central BoB region is dominated by weak easterlies. Then, during the onset pentad, the zonal wind changes direction and increases to $2.4 \mathrm{~ms}^{-1}$ immediately (Fig. 2a). After that, strong westerlies prevail in the central $\mathrm{BoB}$ region, indicating the establishment of the summer monsoon.

Precipitation is also commonly used as an indicator of the summer monsoon onset. Wang and LinHo (2002) proposed a rainfall-based index, derived from the difference between the pentad mean and the January mean precipitation rate, and a critical value of $5 \mathrm{~mm} \mathrm{day}{ }^{-1}$ was used to define the monsoon onset date. Here, the January mean precipitation rate in the central $\mathrm{BoB}$ region is around $2.7 \mathrm{~mm} \mathrm{day}^{-1}$. The composite pentad mean rainfall that exceeds the January mean value by more than $5 \mathrm{~mm}$ day $^{-1}$ for the first time occurs in the onset pentad (Fig. 2b).
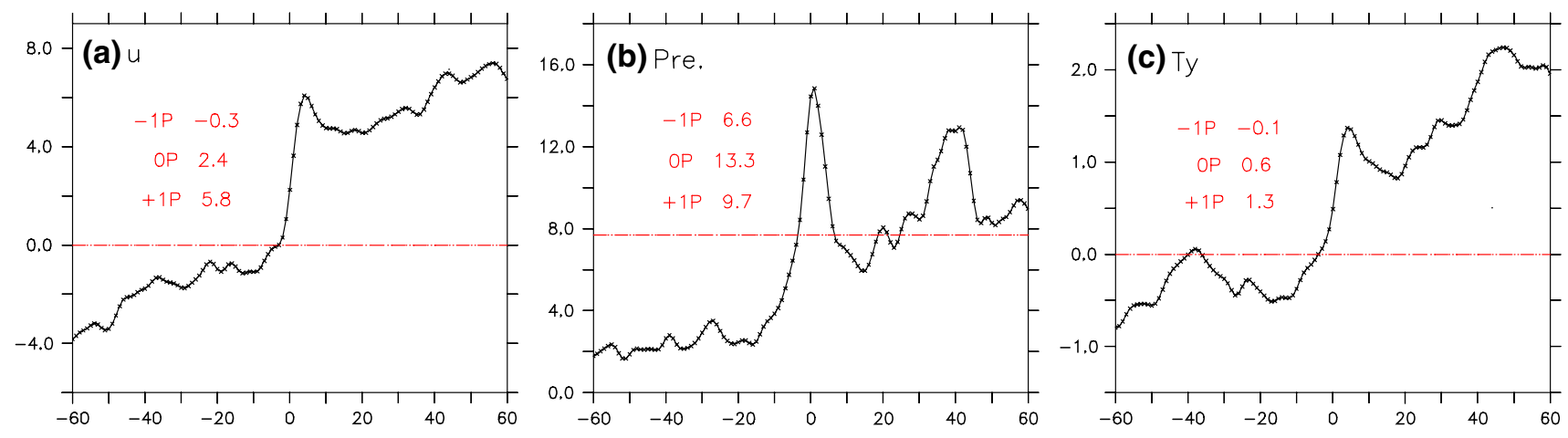

Fig. 2 Composite time evolutions of a surface zonal wind $\left(\mathrm{m} \mathrm{s}^{-1}\right)$, b precipitation rate $\left(\mathrm{mm} \mathrm{day}^{-1}\right)$, and c meridional temperature gradient at $200-500 \mathrm{hPa}\left(10^{-6} \mathrm{~K} \mathrm{~m}^{-1}\right)$ in the central area of the BoB $\left(85^{\circ}-95^{\circ} \mathrm{E}, 7.5^{\circ}-12.5^{\circ} \mathrm{N}\right)$. The mean values in the onset pentad $(0 \mathrm{P})$ as well as the preceding one $(-1 \mathrm{P})$ and the succeeding one $(+1 \mathrm{P})$ are given in each panel. The horizontal axis denotes the relative time (see Fig. 1) 
As a thermally driven circulation, the atmospheric MTG in the lower latitudes changes its sign from negative to positive after the summer monsoon onset. Mao and Wu (2007) proposed the switch of the MTG in the upper troposphere (between 500 and $200 \mathrm{hPa}$ ) as an effective index to define the summer monsoon onset in the $\mathrm{BoB}$ region. In this study, the composite MTG clearly changes its sign in the onset pentad, and remains positive throughout the summer period (Fig. 2c).

From the above comparisons, it is clear that use of our FNISO criterion to define the summer monsoon onset provides a pentad that is generally consistent with those defined by other indices that are based on individual circulation features. In the next section, we discuss the role of the ocean in triggering the FNISOs. We focus on the premonsoon period (PMP), defined as a calm period between day -40 (when the previous equatorially-trapped ISO occurs) and day -10 (when the FNISOs arrive at the equatorial EIO) (Fig. 1). The evolutions of oceanic and atmospheric processes during this critical period substantially alter the propagating feature of the ISOs.

\section{Role of sea surface warming in triggering the FNISOs}

\subsection{Meridional asymmetry of convective instability associated with sea surface processes}

Pronounced seasonality is one of the fundamental features of the tropical ISOs (Zhang and Dong 2004). In the EIO, the ISOs are dominated by an equatorially trapped eastward-propagating mode in winter and a distinct northward-propagating mode in summer. Based on the summer mean state, many theories were proposed to explain the northward propagation, such as ocean-atmosphere interactions (e.g., Kemball-cook and Wang 2001; Fu et al. 2003) and internal atmospheric dynamics (e.g., Jiang et al. 2004; Bellon and Sobel 2008; Kang et al. 2010). However, these explanations are not valid in respect of the FNISOs, because the FNISOs occur during the monsoon transitional season, when the summer mean flow has not yet been established. Inferred from the frictional wave CISK theory (Wang and Rui 1990; Wang and Li 1994; Hendon and Salby 1994), Li et al. (2013) attributed the FNISOs to the Rossby wave destabilization that is induced by a greater convective instability in the $\mathrm{BoB}$ region (which is preestablished in the monsoon transitional season). Based on a deep-layer convective instability index $\left(\theta_{\mathrm{e}}\right.$ at $1000-700 \mathrm{hPa}$ minus $600-300 \mathrm{hPa}$, with $\theta_{\mathrm{e}}$ being the equivalent potential temperature), their diagnosis indicated that the moistureinduced low-level $\theta_{\mathrm{e}}$ plays the dominant role. Therefore, in this paper we focus on the low-level troposphere and explore the critical role of the surface processes associated with the ocean.

During boreal winter, the $\theta_{\mathrm{e}}$ has an almost symmetric structure with its highest values concentrating over the equatorial region in the EIO (Fig. 3a). This favors the unstable Kelvin waves and the convection mainly propagates eastward along the equator. During the boreal summer, the maximum $\theta_{\mathrm{e}}$ values are located at the monsoon trough in the $\mathrm{BoB}$ (Fig. 3b). This striking meridional asymmetry may destabilize the Rossby waves and therefore induce the major convection towards the northern Rossby gyre center from the equator. Once the convective heating is shifted away from the equator, the northward moving systems are likely to be governed by some other mechanisms, related with the summer mean circulations (DeMott et al. 2013).

During the PMP, the $\theta_{\mathrm{e}}$ generally behaves as a transitional mode between the winter and summer (Fig. 3c). While the upper layer maintains the winter mode which is almost symmetric about the equator, an asymmetry is (a) DJF

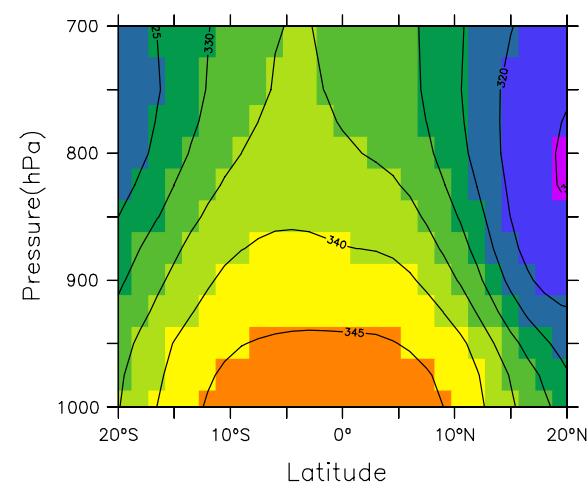

(b) JJA

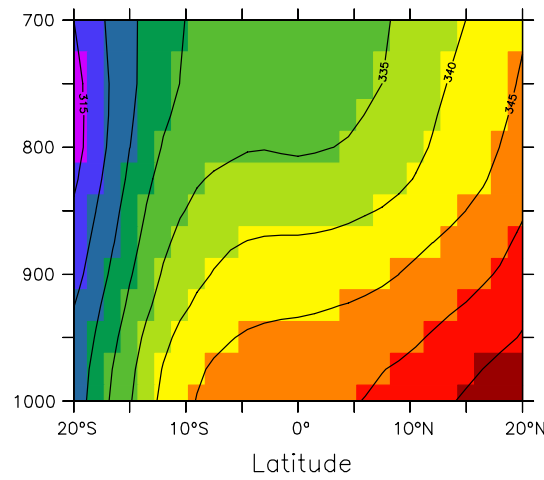

(c) pre-monsoon

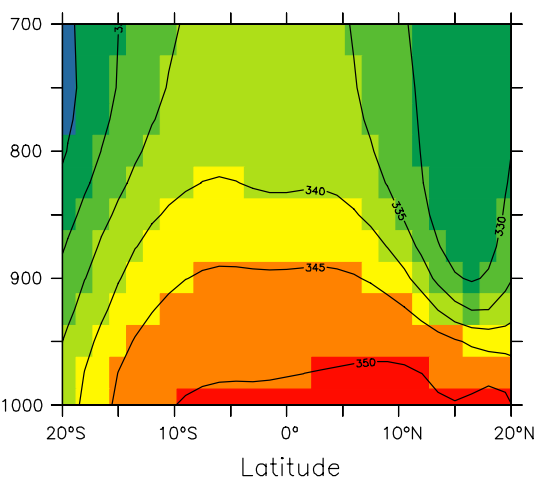

Fig. 3 A meridional-vertical section of the $\theta_{\mathrm{e}}(\mathrm{K})$ in the low-level troposphere along $85^{\circ}-95^{\circ} \mathrm{E}$ in a December-January-February, b June-JulyAugust, and $\mathbf{c}$ the pre-monsoon period 


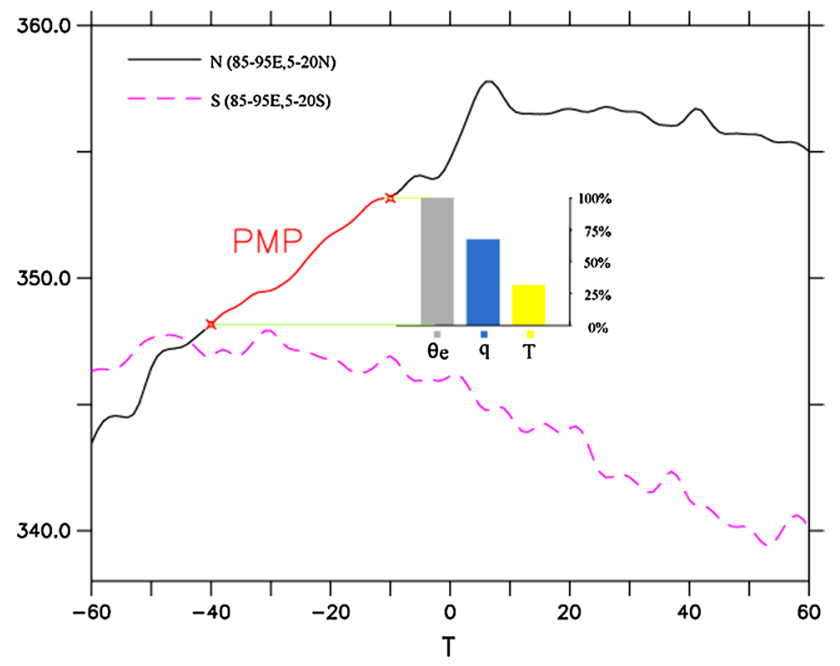

Fig. 4 Temporal evolution of the surface $\theta_{\mathrm{e}}(\mathrm{K})$ in the northern $\left(85^{\circ}-\right.$ $95^{\circ} \mathrm{E}, 5^{\circ}-20^{\circ} \mathrm{N}$; solid line $)$ and southern $\left(85^{\circ}-95^{\circ} \mathrm{E}, 5^{\circ}-20^{\circ} \mathrm{S}\right.$; dashed line) hemispheres of the EIO. The red line highlights evolution of the $\theta_{\mathrm{e}}$ in the northern hemisphere during the pre-monsoon period. The bar graph indicates the total change in the $\theta_{\mathrm{e}}$ (grey) and the partial contributions of air temperature (yellow) and moisture (blue). The horizontal axis denotes the relative time (see Fig. 1)

observed in the surface layer with the maximum $\theta_{\mathrm{e}}$ values having shifted to around $10^{\circ} \mathrm{N}$. Enhanced convective instability is induced in the $\mathrm{BoB}$ region, accompanied by the stronger $\theta_{\mathrm{e}}$ vertical gradient due to the significant surface increase in $\theta_{\mathrm{e}}$. This implies that the ocean plays a leading role in the seasonal evolution of convective instability. As a result of the surface $\theta_{\mathrm{e}}$ asymmetry, the destabilization of the Rossby waves leads to the initiation of the northwardpropagating ISOs during the PMP.

In view of the critical role of sea surface processes, the temporal evolution of the $\theta_{\mathrm{e}}$ at $1000 \mathrm{hPa}$ is examined here (Fig. 4). Compared with a negligible evolution in the southern hemisphere, the $\theta_{\mathrm{e}}$ quickly increases in the northern hemisphere during the PMP. Crossing between the hemispheres only occurs around day -40 when the previous eastward-moving ISO appears. From then on, a distinct meridional contrast gradually forms, which starts the favorable conditions for the onset of the FNISOs.

To understand the relative roles of air temperature and moisture in causing the growth of the surface $\theta_{\mathrm{e}}$ in the BoB region, a diagnosis method following $\mathrm{Li}$ et al. (2013) is conducted. The partial contribution of each parameter is evaluated by a re-calculation of the $\theta_{\mathrm{e}}$, with the other parameter fixed at its value on day -40 . This linear method has been proven capable at separating the partial contributions of air temperature and moisture (Fig. $5 \mathrm{~b}$ in $\mathrm{Li}$ et al. 2013). Based on the above diagnosis, the growth in the $\theta_{\mathrm{e}}$ within the $\mathrm{BoB}$ region by about $5 \mathrm{~K}$ during the PMP is primarily caused by the variations in moisture (about $70 \%$ contribution), and secondarily by the air temperature (about $30 \%$ ).

Due to a relatively smaller contribution to the $\theta_{\mathrm{e}}$ variation, the role of air temperature was not analyzed by $\mathrm{Li}$ et al. (2013). This created a missing link in understanding the $\theta_{\mathrm{e}}$ variation, since the increase of moisture is also dependent on the air temperature, particularly during the calm PMP. Therefore, the importance of the variation in air temperature is clearly identified in the next section, within which the relationships among the SST, air surface temperature and moisture are examined.

\subsection{Impacts of pre-monsoon sea surface warming on the surface $\theta_{\mathrm{e}}$}

As the two main contributors to the $\theta_{\mathrm{e}}$, the air surface temperature $\left(T_{a}\right)$ and moisture are closely related to SST through the surface turbulent heat flux. Before the summer monsoon onset, striking sea surface warming occurs in the BoB region, which could impact on the surface $\theta_{\mathrm{e}}$ by modulating the local $T_{a}$ and moisture. In view of the relationship between the SST and the $T_{a}$, there is a distinct contrast either side (temporally) of the summer monsoon onset (Fig. 5a). Before the summer monsoon onset, the $T_{a}$ generally increases with the SST. During the PMP, the SST increases by about $1.2^{\circ} \mathrm{C}$ and the $T_{a}$ increases by nearly the same proportion (the linear regression coefficient is 0.98 ). After the summer monsoon onset, this relationship suddenly changes and the $T_{a}$ does not correlate well with SST.

A similar feature also occurs between the SST and the specific humidity $(q)$. In the calm PMP, the $q$ gradually increases by more than $1 \mathrm{~g} \mathrm{~kg}^{-1}$ with the increase in SST (Fig. 5c), but there is no clear correlation after the summer monsoon onset. Interestingly, in contrast with the increasing $q$, another humidity parameter, the relative humidity $(r)$ generally remains constant (around $78 \%$ ) during the calm PMP (Fig. 5d). In relation to this, the question arises of how we can understand the relationships among the SST, $T_{a}, q$ and $r$ during the PMP?

In fact, the increase of the $q$ in the calm PMP occurs due to the warmer air being able to hold more water vapor, as dictated by the Clausius-Clapeyron $(\mathrm{C}-\mathrm{C})$ relationship, under the condition that the $r$ remains constant. To show this, we consider a formula of the $\mathrm{C}-\mathrm{C}$ relationship for water vapor under typical atmospheric conditions:

$\frac{d e_{s}}{e_{s}}=\frac{L}{R T^{2}} d T$

where $e_{s}$ is the saturation vapor pressure, $R$ is the specific gas constant, $L$ is the specific latent heat, and $T$ is the temperature in Kelvin. Given a reference temperature of $26.5{ }^{\circ} \mathrm{C}$ (Fig. $5 \mathrm{~b}$ ), theoretically, the $e_{s}$ would increase by about $6 \%$ with a $1{ }^{\circ} \mathrm{C}$ warming. This means that the 


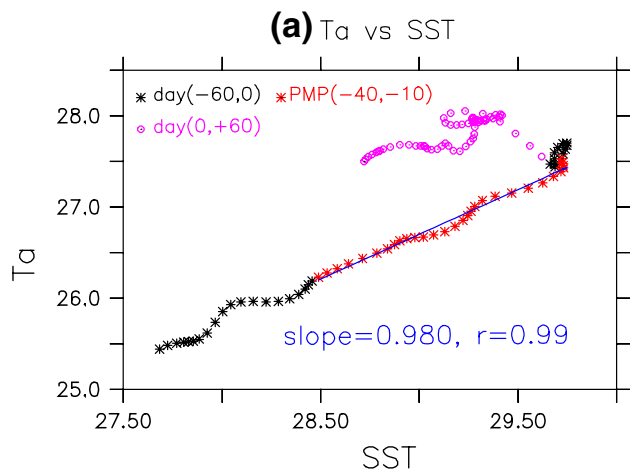

(c) q vs SST

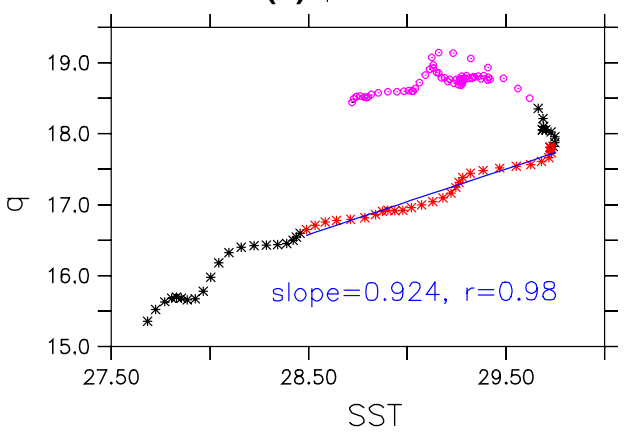

Fig. 5 Composite relationships, derived from the ERA-Interim reanalysis in the region $\left(85^{\circ}-95^{\circ} \mathrm{E}, 5^{\circ}-20^{\circ} \mathrm{N}\right)$, between the a SST and air surface temperature, $\mathbf{b}$ air surface temperature and specific humidity, c SST and surface specific humidity, and $\mathbf{d}$ air surface temperature

$q$ would increase by almost the same proportion under a constant $r$. In the observations, the $q$ increases at a rate of $5.6 \%{ }^{\circ} \mathrm{C}^{-1}$ at the reference temperature of $26.5{ }^{\circ} \mathrm{C}$ (Fig. 5b). This observed rate of increase is quite close to the theoretical rate.

To verify the relationships among the SST, $T_{a}, q$ and $r$ revealed in the reanalysis data, in situ data from the RAMA buoys is used for comparison. The RAMA project was conducted to improve descriptions, understanding, and predictions of the east Africa, Asian and Australian monsoon systems. There are three buoys in our study area, located at $8^{\circ} \mathrm{N}, 12^{\circ} \mathrm{N}$, and $15^{\circ} \mathrm{N}$, and $90^{\circ} \mathrm{E}$, respectively. The $T_{a}$ and $r$ are measured at $3 \mathrm{~m}$ above the sea surface, while the SST comprises the water temperature at $1 \mathrm{~m}$ below the sea surface. The composite relationships among the above parameters are shown in Fig. 6, based on 5 years of data from 2008 to 2012. Some missing observations from 2008 to 2012 are excluded from the composite and the reference date (day 0) is determined by the OLR field in Fig. 1.

The in situ observations give a similar result to the reanalysis data. The distinct contrasts with regard to the summer monsoon onset are clearly observed in the SST$T_{a}$, SST $-q, T_{a}-q$, and $T_{a}-r$ relationships. During the PMP,

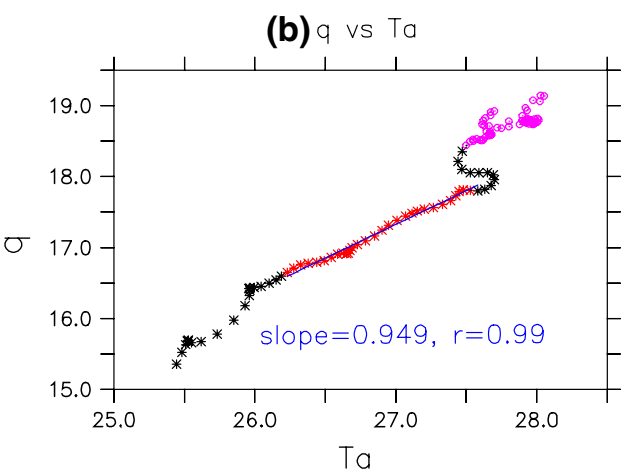

(d) $r$ vs Ta

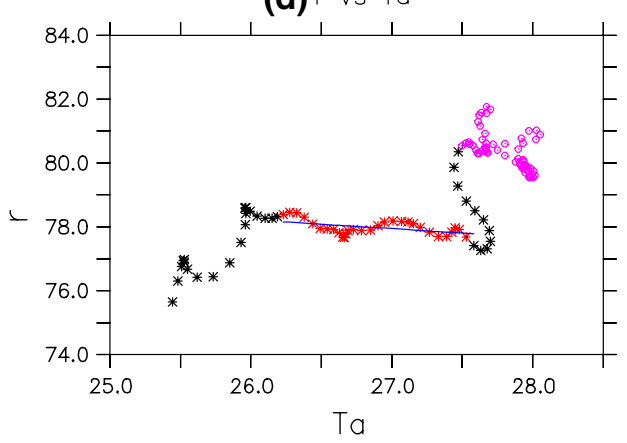

and relative humidity. The purple circles indicate the period of day 0 to day +60 , and the asterisks represent the period of day -60 to day 0 with the pre-monsoon period being highlighted in red. The linear regressions for the pre-monsoon period are given in $(\mathbf{a}-\mathbf{c})$

the $T_{a}$ increases at nearly the same proportion (the linear regression coefficient is 0.97) as the SST (Fig. 6a). The $q$ increases with $T_{a}$ at a rate of $5.7 \%{ }^{\circ} \mathrm{C}^{-1}$ at the reference temperature of $28.5^{\circ} \mathrm{C}$ (Fig. 6b), and the $r$ is generally stable (at about $76 \%$; Fig. 6d). The observed rate of increase for the $q$ is very close to the theoretical value of $5.9 \%{ }^{\circ} \mathrm{C}^{-1}$, according to the $\mathrm{C}-\mathrm{C}$ relationship at the reference temperature of $28.5^{\circ} \mathrm{C}$ under a constant $r$. After the summer monsoon onset, the above relationships significantly change.

Even the $r$ is probably influenced by the atmospheric circulations or mixing, the marine surface air tends to reach a certain level of saturation (75-80 \%), which bears some spatial homogeneity and temporal invariance (Dai 2006). An experiment by Wexler and Hasegawa (1954) also showed that the equilibrium of $r$ over saturated sodium chloride $(\mathrm{NaCl})$ solution is about $75-76 \%$, which is independent of temperature. During the PMP, the sea surface $r$ keeps the saturation levels at 76-78\%, which is close to the equilibrium value found by Wexler and Hasegawa (1954). This implies that the sea surface status in the PMP is calm enough to maintain the $r$ at equilibrium. 

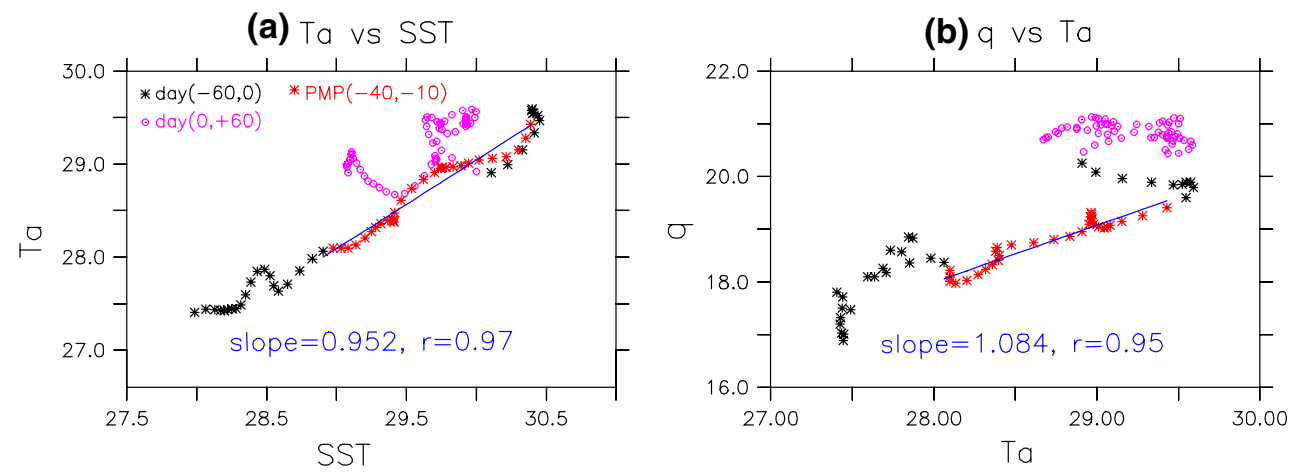

(c) q vs SST
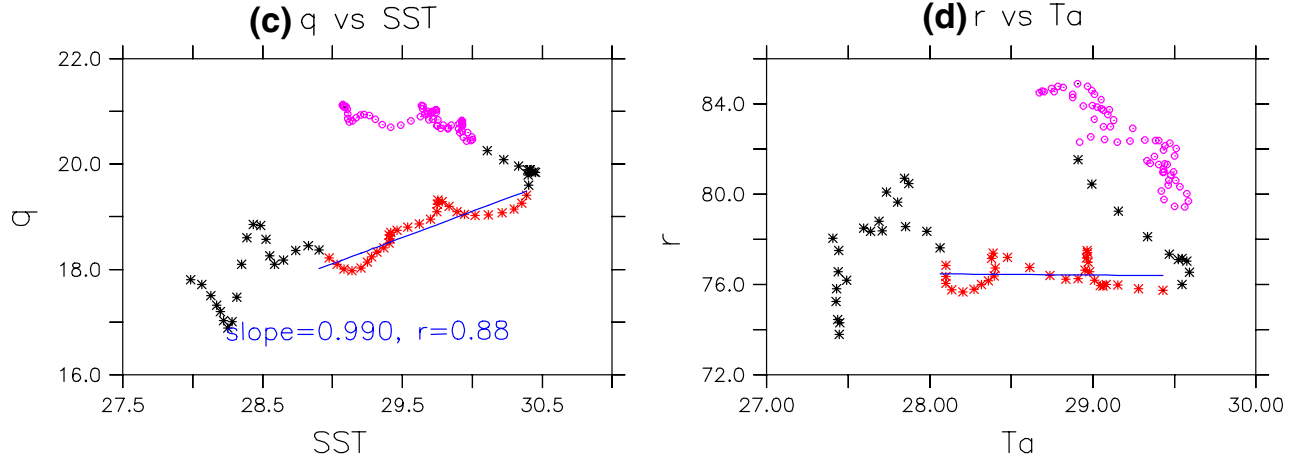

Fig. 6 As Fig. 5, but for the RAMA buoys data during 2008-2012

\subsection{Surface moisture increases associated with evaporation}

We have shown that surface moisture dominates the growth of the $\theta_{\mathrm{e}}$ in the $\mathrm{BoB}$ region during the PMP (Fig. 4). The increase in moisture is preconditioned by the elevated water vapor capacity, as a result of the warmer surface air. Then, the question is: where does the additional moisture come from? To examine the specific processes responsible for the variations in moisture, a moisture budget is considered (Yanai et al. 1973):

$\frac{\partial q}{\partial t}=-\mathbf{V}_{h} \cdot \nabla q-w \cdot \frac{\partial q}{\partial p}-Q_{2} / L$

where $q$ is the specific humidity, $\mathbf{V}_{h}$ is the horizontal velocity, $w$ is the p-vertical velocity, $Q_{2}$ is the apparent moisture sink, and $L$ is the latent heat constant. In the above equation, $-\mathbf{V}_{h} \cdot \nabla q$ denotes the horizontal moisture advection, $-w \cdot \frac{\partial q}{\partial p}$ indicates the vertical moisture advection, and $-Q_{2} / L$ represents the moisture source or sink (which is primarily determined by the surface evaporation and atmospheric condensation). The diagnosis is applied to the $1000 \mathrm{hPa}$ layer over the BoB region during the PMP.

A positive moisture tendency dominates the whole of the basin of the BoB during the PMP (Fig. 7a). In regard of the positive tendency, the horizontal advection term generally has a negative contribution, although there are some positive values over the eastern and northern areas of the bay (Fig. 7b). Owing to the prevailing subsidence resulting from the land-ocean thermal contrasts, negative vertical moisture advection is induced in the BoB region during the PMP (Fig. 7c). In one word, the increase in moisture primarily comes from the moisture source term (Fig. 7d). Through a quantitative comparison, the moisture source term $\left(0.32 \mathrm{~g} \mathrm{day}^{-1}\right)$ appears to be almost one order of magnitude higher than the total moisture tendency $\left(0.04 \mathrm{~g}\right.$ day $\left.^{-1}\right)$. Importantly, this indicates that the increase of surface moisture is basically dependent on the elevated water vapor capacity due to the air temperature, rather than a more powerful source supply.

At $1000 \mathrm{hPa}$, the moisture source term is mainly controlled by sea surface evaporation. Hence, the temporal evolution of the surface evaporation is examined here, with the aid of an empirical equation that is based on oceanic and atmospheric surface parameters:

$E \approx \rho C V\left(q_{s}\left(T_{o}\right)-r q_{s}\left(T_{a}\right)\right)$

where $E$ is the evaporation rate, $\rho$ is the air density, $C$ is an exchange coefficient, $V$ is the near-surface wind speed, $r$ is the relative humidity, and $q_{s}(T)$ is the saturation of specific humidity at the temperature $T$, with subscripts $o$ and $a$ denoting the ocean and air surface temperatures, respectively. 

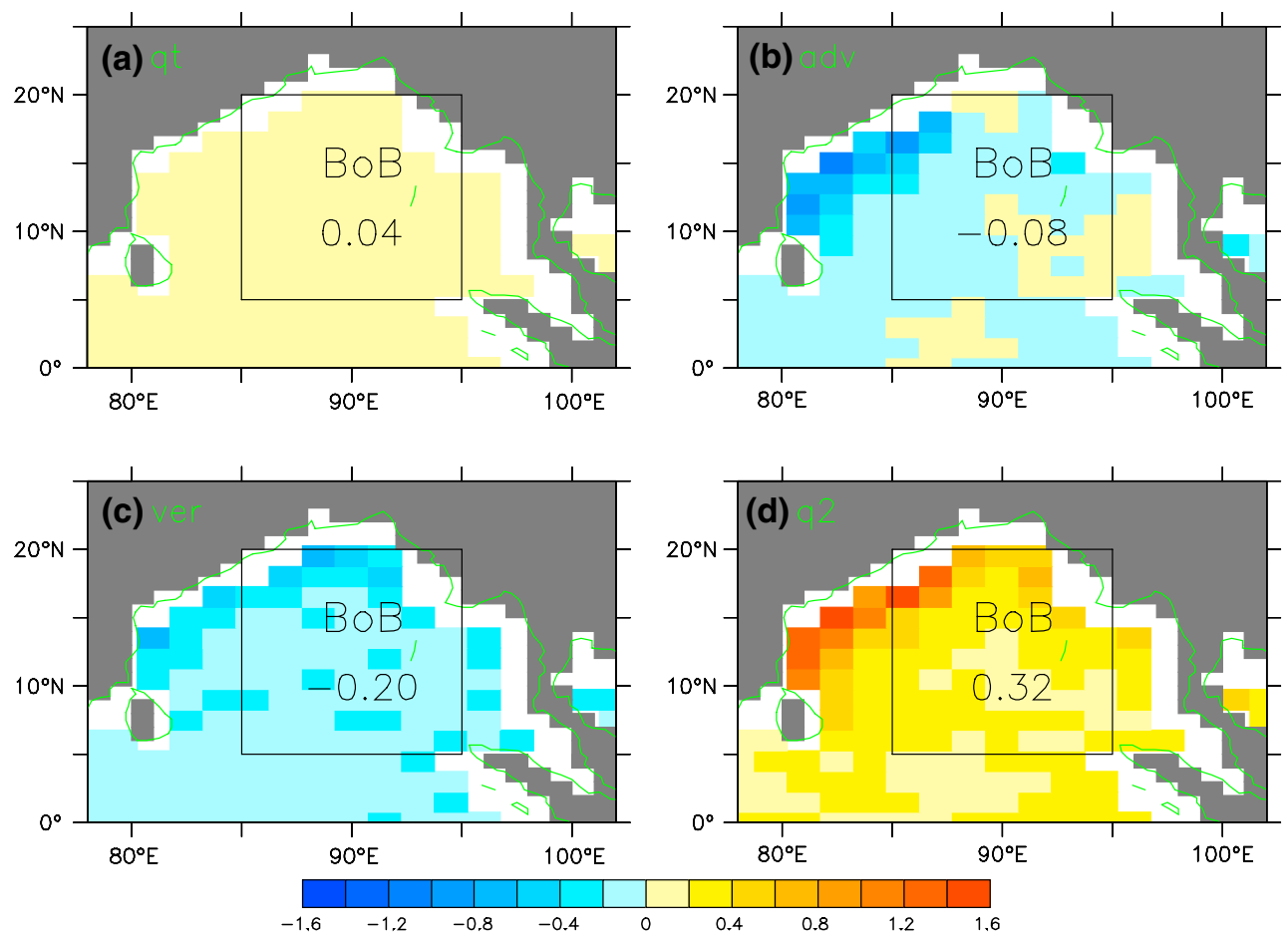

Fig. 7 The spatial distributions of the a specific humidity tendency, b horizontal moisture advection term, c vertical moisture advection term, and $\mathbf{d}$ moisture source term $\left(\mathrm{g} \mathrm{day}^{-1}\right)$ at the sea surface during
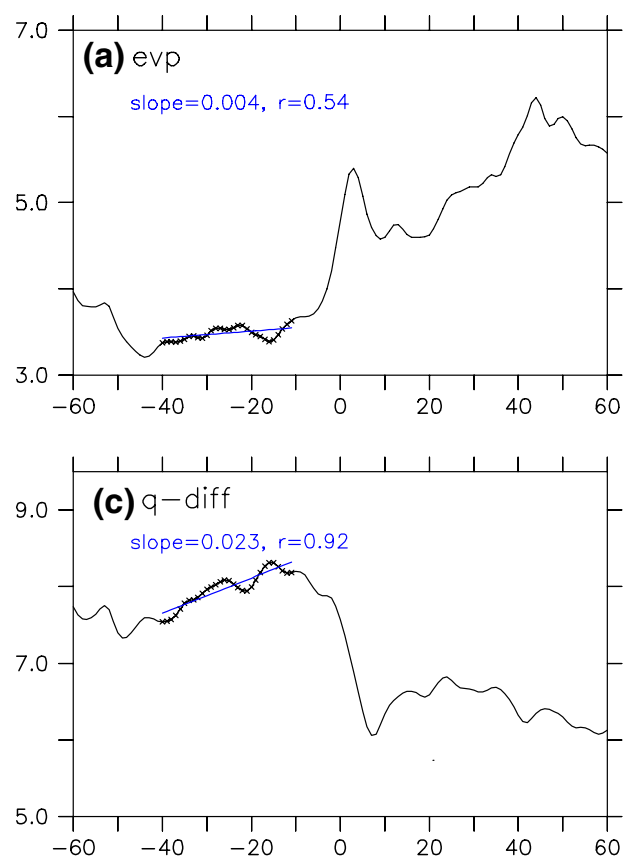

Fig. 8 The composite temporal evolutions of the average a sea surface evaporation $\left(\mathrm{g} \mathrm{day}^{-1}\right)$, b surface wind speed $\left(\mathrm{m} \mathrm{s}^{-1}\right)$, $\mathbf{c} q_{s}\left(T_{o}\right)$ $r q_{s}\left(T_{a}\right)\left(\mathrm{g} \mathrm{kg}^{-1}\right)$, and d $\operatorname{SST}\left({ }^{\circ} \mathrm{C}\right)$ within the region $\left(85^{\circ}-95^{\circ} \mathrm{E}\right.$, the pre-monsoon period. The average value within the $\mathrm{BoB}$ (denoted by the box) is given in each panel
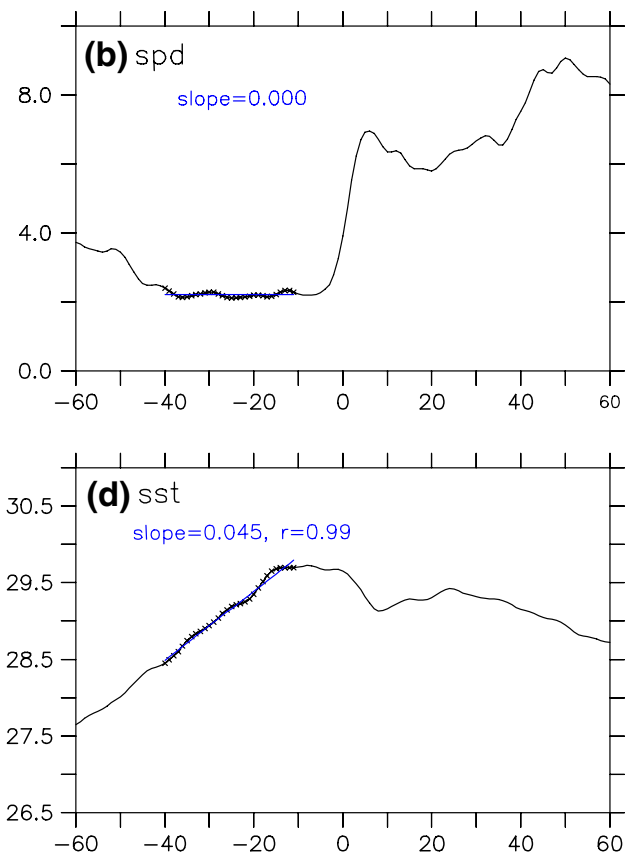

$\left.5^{\circ}-20^{\circ} \mathrm{N}\right)$. The linear regressions for the pre-monsoon period are given in each panel. The horizontal axis denotes the relative time (see Fig. 1) 
To a large extent, the surface evaporation rate (Fig. 8a) is dominated by the wind speed variation (Fig. 8b). During the PMP, the rate of evaporation is generally low as a result of the weak wind. Still, an increasing trend is observed in the presence of the nearly stable wind. Naturally, this increase in evaporation would be attributed to sea surface warming, through its contribution to the humidity gradient term, that is, $q_{s}\left(T_{o}\right)-r q_{s}\left(T_{a}\right)$. During the PMP, the $T_{a}$ always follows the SST (the linear regression coefficient approximates to 1 ; Fig. 5a); in other words, $T_{a} \approx T_{o}-\Delta T$, with $\Delta T\left(\approx 1.7^{\circ} \mathrm{C}\right.$, Fig. 5a) being a nearly constant temperature difference between the ocean and air surface. Under these conditions, $q_{s}\left(T_{o}\right)-r q_{s}\left(T_{a}\right)$ exhibits an increasing trend (Fig. 8c) in response to sea surface warming (Fig. 8d). Thus, given the fact that the changes of $\rho, C, V$ and $r$ are negligible during the calm PMP, it is the increase in SST that ultimately induces the increase in evaporation rate.

Until now, it has been possible to understand the schematic map, with regard to the impacts of sea surface warming on the growth of the surface $\theta_{\mathrm{e}}$ during the PMP (Fig. 9). During this period, strong sea surface heating induces an increasing trend in SST, and the prevailing subsidence largely suppresses small-scale disturbances over the BoB region. Under the calm weather, the surface air (including its temperature and humidity) is dominantly modulated by the sea surface processes and they evolve nearly in equilibrium. The impact of sea surface warming on the growth of the surface $\theta_{\mathrm{e}}$ is considered in the following ways. Firstly, warming SST heats the surface air through sensible heating. The observations show that the $T_{a}$ increases almost proportionally with the SST. In this way, $T_{a}$ accounts for $30 \%$ of the growth in the surface $\theta_{\mathrm{e}}$ during the PMP. Furthermore, the increase of $T_{a}$ raises the water vapor capacity of the surface air that is able to accommodate more moisture. Under the calm conditions, the $q$ increases along with the enhanced water vapor capacity, while the $r$ is maintained at equilibrium. This additional moisture is primarily obtained from the sea surface evaporation. In this way,

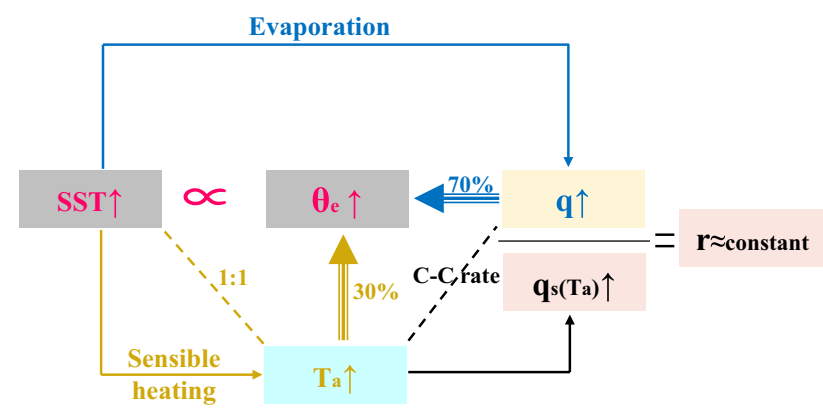

Fig. 9 A schematic diagram indicating the relationship between sea surface warming and growth of the surface $\theta_{e}$ within the $\mathrm{BoB}$ during the calm pre-monsoon period it contributes about $70 \%$ to the growth in the surface $\theta_{\mathrm{e}}$. Therefore, accompanied with the sea surface warming, the surface $\theta_{\mathrm{e}}$ increases in the BoB region and eventually contributes a meridional asymmetry of convective instability in the EIO during the PMP. The latter thus preconditions the FNISOs.

\section{Conclusions and discussion}

During the monsoon transitional period, complex oceanatmosphere-land interactions around South Asia lead to a striking sea surface warming in the central areas of the BoB. This warming has primarily been attributed to the enhanced solar heating, in conjunction with the shallow oceanic mixed layer due to the weak wind conditions ( $\mathrm{Wu}$ et al. 2012; Liu et al. 2013). The SST reaches its annual maximum just before the summer monsoon onset and collapses soon after it in the central BoB region. In this study, the role of the peak in pre-monsoon SST in triggering the summer monsoon onset has been investigated, with an emphasis on how they drive the FNISOs over the equatorial EIO.

$\mathrm{Li}$ et al. (2013) pointed out the uniqueness of the FNISOs, in comparison with general northward-propagating boreal summer ISO events. A pre-established meridional asymmetry of convective instability in the EIO was considered to favor the northward shift of the FNISO convections. In-depth analysis in the present study has shown that the above asymmetry can be traced back to the surface layer, where the oceanic processes are dominant. It is the quick growth of surface $\theta_{\mathrm{e}}$ in the $\mathrm{BoB}$ region, caused by sea surface warming, that fundamentally accounts for the northward movement of the FNISOs.

Under the calm conditions during the PMP, the surface air evolves in equilibrium with the sea surface processes. The $T_{a}$ is forced to increase at nearly the same rate as the SST, while the surface relative humidity is maintained at equilibrium around 76-78\%. The evolution of the $T_{a}$ plays an important role in the growth of the $\theta_{\mathrm{e}}$ during the PMP. In addition to its direct contribution, the $T_{a}$ also governs the increasing rate of moisture, through modulating the water vapor capacity of the surface air. Diagnosis has revealed that the increasing moisture is primarily obtained from evaporation, which is also closely related to sea surface warming during the PMP. Therefore, accompanied with the sea surface warming, the surface $\theta_{\mathrm{e}}$ increases in the $\mathrm{BoB}$, and eventually contributes to a meridional asymmetry of convective instability in the EIO during the PMP. As a result, a northward shift is induced when the eastward-propagating ISO convections arrive at the EIO. The FNISOs then trigger the summer monsoon onset over the BoB. 
The stable relationships among the daily SST, $T_{a}$, humidity and evaporation are conditionally observed during the calm PMP in this study, when small-scale disturbances are largely suppressed by the prevailing subsidence. These relationships change dramatically and are not obvious during the summer season, when synoptic-scale disturbances are active (Fig. 5). Thus the results from this study should be treated cautiously if applied for other seasons or in other basins.

The present in-depth study considers one mechanism of the FNISOs proposed in Li et al. (2013). We have highlighted the role of pre-monsoon sea surface warming in preconditioning the FNISOs, and have focused our effort on understanding the underlying physical processes that are responsible for the increase of air surface temperature and moisture associated with the SST. This study provides a new insight on the interaction of oceanic process and monsoon variability. The oceanic processes do not just trigger the summer monsoon onset through the initiation of the northward-moving convection. In addition, coupling with the pre-monsoon shallow warm mixed layer in the BoB usually creates the strongest FNISOs in a year (Bellenger and Duvel 2007). Therefore, this reinforced convection can powerfully recoil the environmental conditions of the transitional season and substantially alter the basic state to form another phase of the monsoon cycle.

We have proposed and verified the criterion of FNISOs as an index to determine the summer monsoon onset in the $\mathrm{BoB}$ region. The potential application of this index could promote the prediction of the summer monsoon onset, because the ISOs can be predicted more than 2 weeks in advance based on recent studies (Goswami and Xavier 2003; Webster and Hoyos 2004; Jones et al. 2004). Further theoretical analysis or modeling validation would strengthen our results.

Acknowledgments This work was supported by NSFC-Shandong Joint Fund for Marine Science Research Centers Grant No. U1406404, by Chinese Ministry of Science and Technology under Contract No. 2012DFB20210, by the Basic Scientific Fund for National Public Research Institutes of China Nos. 2014G03 and 2011G22, and by NSFC Grant No. 41005032.

\section{Compliance with ethical standard}

Conflict of interest Kuiping Li, Yanliang Liu, Yang Yang, Zhi Li, Baochao Liu, Liang Xue, and Weidong Yu declare that they have no conflicts of interest regarding the publication of this paper.

Open Access This article is distributed under the terms of the Creative Commons Attribution 4.0 International License (http://creativecommons.org/licenses/by/4.0/), which permits unrestricted use, distribution, and reproduction in any medium, provided you give appropriate credit to the original author(s) and the source, provide a link to the Creative Commons license, and indicate if changes were made.

\section{References}

Annamalai H, Liu P, Xie SP (2005) Southwest Indian Ocean SST variability: its local effect and remote influence on Asian monsoons. J Clim 18(20):4150-4167

Bellenger H, Duvel JP (2007) Intraseasonal convective perturbations related to the seasonal march of the Indo-Pacific monsoons. J Clim 20(12):2853-2863

Bellon G, Sobel AH (2008) Instability of the axisymmetric monsoon flow and intraseasonal oscillation. J Geophys Res 113:D07108. doi:10.1029/2007JD009291

Dai A (2006) Recent climatology, variability, and trends in global surface humidity. J Clim 19(15):3589-3606

Dee DP et al (2011) The ERA-interim reanalysis: configuration and performance of the data assimilation system. Quart J Roy Meteor Soc 137:553-597

DeMott CA, Stan C, Randall DA (2013) Northward propagation mechanisms of the boreal summer intraseasonal oscillation in the ERA-Interim and SP-CCSM. J Clim 26(6):1973-1992

Ding Y, He C (2006) The summer monsoon onset over the tropical eastern Indian Ocean: the earliest onset process of the Asian summer monsoon. Adv Atmos Sci 23(6):940-950

Flatau MK, Flatau PJ, Rudnick D (2001) The dynamics of double monsoon onsets. J Clim 14(21):4130-4146

Fu X, Wang B, Li T, McCreary J (2003) Coupling between northward-propagating, intraseasonal oscillations and sea surface temperature in the Indian Ocean. J Atmos Sci 60(15):1733-1753

Goswami BN, Xavier PK (2003) Potential predictability and extended range prediction of Indian summer monsoon breaks. Geophys Res Lett. doi:10.1029/2003GL017810

Hendon HH, Salby ML (1994) The life cycle of the Madden-Julian oscillation. J Atmos Sci 51(15):2225-2237

Hsu HH, Terng CT, Chen CT (1999) Evolution of large-scale circulation and heating during the first transition of Asian summer monsoon. J Clim 12:793-810

Jiang X, Li J (2011) Influence of the annual cycle of sea surface temperature on the monsoon onset. J Geophys Res 116:D10105. doi: 10.1029/2010JD015236

Jiang X, Li T, Wang B (2004) Structures and mechanisms of the northward propagating boreal summer intraseasonal oscillation. J Clim 17:1022-1039

Jones C, Carvalho LMV, Higgins RW, Waliser DE, Schemm JKE (2004) A statistical forecast model of tropical intraseasonal convective anomalies. J Clim 17:2078-2095

Kang IS, Kim D, Kug JS (2010) Mechanism for northward propagation of boreal summer intraseasonal oscillation: convective momentum transport. Geophys Res Lett 37:L24804. doi:10.102 9/2010GL045072

Kemball-Cook SR, Wang B (2001) Equatorial waves and air-sea interaction in the boreal summer intraseasonal oscillation. J Clim 14:2923-2942

Krishnamurti TN, Ardanuy P, Ramanathan Y, Pasch P (1981) On the onset vortex of the summer monsoon. Mon Wea Rev 109(2):344-363

Lau KM, Yang S (1997) Climatology and interannual variability of the Southeast Asian summer monsoon. Adv Atmos Sci 14(2):141-162

Li J, Zhang L (2009) Wind onset and withdrawal of Asian summer monsoon and their simulated performance in AMIP models. Clim Dyn 32(7-8):935-968

Li J, Wu G, Hu D (2011) Ocean-atmosphere interaction over the joining area of Asia and Indian-Pacific Ocean and its impact on the short-term climate variation in China. China Meteorological Press, Beijing, pp 1-516 (in Chinese) 
Li K, Yu W, Li T, Murty VSN, Khokiattiwong S, Adi TR, Budi S (2013) Structures and mechanisms of the first-branch northwardpropagating intraseasonal oscillation over the tropical Indian Ocean. Clim Dyn 40(7-8):1707-1720

Li K, Li Z, Yang Y, Xiang B, Liu Y, Yu W (2015) Strong modulations on the Bay of Bengal monsoon onset vortex by the first northward-propagating intra-seasonal oscillation. Clim Dyn. doi:10.1007/s00382-015-2826-4

Liebmann B, Smith CA (1996) Description of a complete (interpolated) outgoing longwave radiation dataset. Bull Am Meteorol Soc 77:1275-1277

LinHo, Wang B (2002) The time-space structure of the AsianPacific summer monsoon: a fast annual cycle view. J Clim 15:2001-2019

Liu Y, Yu W, Li K, Li Z, Wang H, Gao L (2013) Mixed layer heat budget in Bay of Bengal: Mechanism of the generation and decay of spring warm pool. Acta Oceanologica Sinica 35(6):1-8 (in Chinese)

Madden RA, Julian PR (1971) Detection of a 40-50 day oscillation in the zonal wind in the tropical Pacific. J Atmos Sci 28:702-708

Madden RA, Julian PR (1972) Description of global-scale circulation cells in the tropics with a $40-50$ day period. J Atmos Sci 29:3138-3158

Mao J, Wu G (2007) Interannual variability in the onset of the summer monsoon over the eastern Bay of Bengal. Theor Appl Climatol 89(3-4):155-170

McPhaden MJ et al (2009) RAMA: the research moored array for African-Asian-Australian monsoon analysis and prediction. Bull Am Meteorol Soc 90(4):459-480

Reynolds RW, Smith TM, Liu C, Chelton DB, Casey KS, Schlax MG (2007) Daily high-resolution-blended analyses for sea surface temperature. J Clim 20(22):5473-5496

Sperber KR, Annamalai H, Kang I-S, Kitoh A, Moise A, Turner A, Wang B, Zhou T (2013) The Asian summer monsoon: an intercomparison of CMIP5 vs. CMIP3 simulations of the late 20th century. Clim Dyn 41:2711-2744

Tong HW, Chan JCL, Zhou W (2009) The role of MJO and mid-latitude fronts in the South China Sea summer monsoon onset. Clim Dyn 33(6):827-841

Wang B, Li T (1994) Convective interaction with boundary-layer dynamics in the development of a tropical intraseasonal system. J Atmos Sci 51:1386-1400
Wang B, LinHo (2002) Rainy season of the Asian-Pacific summer monsoon. J Clim 15:386-398

Wang B, Rui H (1990) Dynamics of the coupled moist KelvinRossby wave on an equatorial $\beta$-plane. J Atmos Sci 47:397-413

Wang B, Xu X (1997) Northern hemisphere summer monsoon singularities and climatological intraseasonal oscillation. J Clim 10(5):1071-1085

Wang B, LinHo, Zhang Y, Lu MM (2004) Definition of South China Sea monsoon onset and commencement of the East Asia summer monsoon. J Clim 17:699-710

Webster PJ (2006) The coupled monsoon system. In: Wang B (ed) The Asian Monsoon. Springer, Berlin, pp 3-66

Webster PJ, Hoyos C (2004) Prediction of monsoon rainfall and river discharge on 15-30-day time scales. Bull Am Meteor Soc 85:1745-1765

Wexler A, Hasegawa S (1954) Relative humidity-temperature relationships of some saturated salt solutions in the temperature range 0 to 50 C. J Res Nat Bureau Stand 53(1):19-26

Wu G, Zhang Y (1998) Tibetan Plateau forcing and the timing of the monsoon onset over South Asia and the South China Sea. Mon Wea Rev 126(4):913-927

Wu G, Guan Y, Liu Y, Yan J, Mao J (2012) Air-sea interaction and formation of the Asian summer monsoon onset vortex over the Bay of Bengal. Clim Dyn 38(1-2):261-279

Yanai M, Esbensen S, Chu JH (1973) Determination of bulk properties of tropical cloud clusters from large-scale heat and moisture budgets. J Atmos Sci 30:611-627

Yasunari T (1979) Cloudiness fluctuations associated with the northern hemisphere summer monsoon. J Meteorol Soc Jpn $57: 227-242$

Yu W, Shi J, Liu L, Li K, Liu Y, Wang H (2012) The onset of the monsoon over the Bay of Bengal: the observed common features for 2008-2011. Atmos Oceanic Sci Lett 5:314-318

Zhang C, Dong M (2004) Seasonality in the Madden-Julian oscillation. J Clim 17(16):3169-3180

Zhou L, Murtugudde R (2014) Impact of northward-propagating intraseasonal variability on the onset of Indian summer monsoon. J Clim 27:126-139 